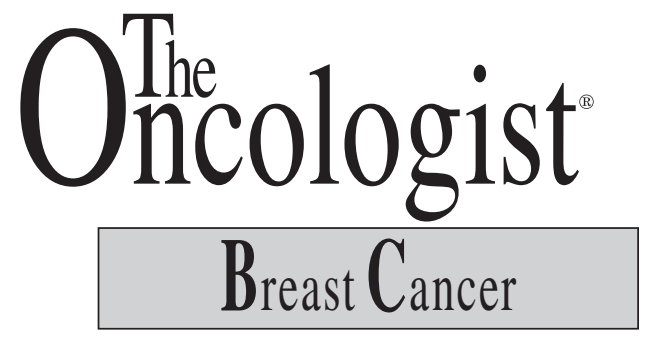

This material is protected by U.S. Copyright law. Unauthorized reproduction is prohibited.

For reprints contact: Reprints@AlphaMedPress.com

\title{
Aromatase Inhibitors in Breast Cancer: An Overview
}

\author{
KADRi Altundag, ${ }^{\mathrm{a}, \mathrm{b}}$ Nuhad K. Ibrahim ${ }^{\mathrm{b}}$ \\ aDepartment of Breast Medical Oncology, The University of Texas M. D. Anderson Cancer Center, Houston, \\ Texas, USA; ' Department of Medical Oncology, Hacettepe University Faculty of Medicine, Ankara, Turkey
}

Key Words. Breast cancer • Hormone receptor-positive • Aromatase inhibitor

\section{LEARNing OBJECTIVES}

After completing this course, the reader will be able to:

1. Discuss the published data on aromatase inhibitors in breast cancer.

2. Describe the differences in study designs, clinical outcome, and safety data on aromatase inhibitors.

3. Select the proper aromatase inhibitor based on a thorough understanding of the data that led to the specific indication for the drug.

\section{CME Access and take the CME test online and receive 1 AMA PRA category 1 credit at CME.TheOncologist.com}

\section{Abstract}

We examined published reports on the use of aromatase inhibitors in postmenopausal patients with hormone receptor-positive breast cancer. Our data were obtained through a MEDLINE search of literature published in English. Current data indicate that aromatase inhibitors are equivalent or superior to tamoxifen as first-line therapy for metastatic breast cancer and as neoadjuvant treatment for primary breast cancer. In addition, randomized studies have shown that aromatase inhibitors can be administered instead of tamoxifen as a single agent for 5 years or sequentially with tamoxifen for 5 or 10 years. These choices should be discussed with the patient, considering the estimated risk for recurrence and other associated comorbid conditions such as osteoporosis and thromboembolism. The Oncologist 2006;11:553-562

\section{INTRODUCTION}

An estimated $75 \%$ of breast cancers test positive for the estrogen receptor (ER), the progesterone receptor (PgR), or both, and estrogen stimulation of these receptors is a significant factor in the development and growth of breast cancer. Ever since oophorectomy was first shown to cause regression of advanced breast cancer more than a century ago, deprivation of estrogenic signaling has been the mainstay of endocrine management of ER-positive and/or PgR-positive disease [1].
Tamoxifen inhibits the growth of breast cancer through competitive antagonism of estrogen at its receptor. Tamoxifen also has some estrogen-agonist effects that help prevent bone demineralization in postmenopausal women and improve their lipid profiles [2]. The Early Breast Cancer Trialists' Collaborative Group showed that 5 years of adjuvant tamoxifen therapy reduced mortality by $31 \%$ [3]. Unfortunately, tamoxifen increases the risk for endometrial cancer by 2.4 times and the risk for thromboembolic disease by 1.9 times [4]. Furthermore, despite adjuvant

Correspondence: Nuhad K. Ibrahim, M.D., Department of Breast Medical Oncology, Unit 424, The University of Texas M. D. Anderson Cancer Center, 1515 Holcombe Boulevard, Houston, Texas 77030-4009, USA. Telephone: 713-792-2817; Fax: 713-794-4385; e-mail: nibrahim@mdanderson.org Received January 19, 2005; accepted for publication April 11, 2006. CAlphaMed Press 1083$7159 / 2006 / \$ 20.00 / 0$ 
tamoxifen treatment for 5 years, cancer relapses continue even beyond 15 years after therapy [5]. Therefore, an alternative or additional hormonal therapy may help reduce breast cancer mortality more than tamoxifen does and have a more favorable toxicity profile.

Aromatase, an enzyme of the cytochrome P-450 super family and the product of the CYP19 gene, is expressed in several tissues, including subcutaneous fat, liver, muscle, brain, normal breast tissues, and mammary adenocarcinoma [6]. It is responsible for the conversion of the adrenal androgen substrate androstenedione to estrogen in peripheral tissues (Fig. 1) [7], the predominant source of estrogen in postmenopausal women. Aromatase inhibitors (AIs) can reduce estrogen production by more than $90 \%[8$, 9]. Unlike tamoxifen, however, AIs lack estrogen-agonist activity. Because AIs do not affect the ovarian production of estrogen, only women without functioning ovaries can benefit from the use of AIs.

AIs are classified as first, second, or third generation according to the specificity and potency with which they inhibit the aromatase enzyme. They are further subclassified as type 1 or type 2 inhibitors, according to the reversibility of their inhibitory activity (Table 1). Type 1 inhibitors, steroidal analogues of androstenedione, irreversibly inhibit the aromatase enzyme by covalently binding to it, thus earning the name "suicidal inhibitors." Permanent inactivation persists after discontinuation of the drug until the peripheral tissues synthesize new enzymes. In contrast, nonsteroidal type 2 inhibitors bind reversibly to the aromatase enzyme, resulting in competitive inhibition [10]. Third-generation AIs (i.e., anastrozole, letrozole, and exemestane) are the most potent, most selective, and least toxic AIs known today and can reduce serum estrogen by more than $95 \%$. In addition, their pharmacokinetic properties (a half-life of approximately 48 hours for anastrozole and letrozole and 27 hours for exemestane) allow for a once-daily dosing schedule [11-13]. Their selective

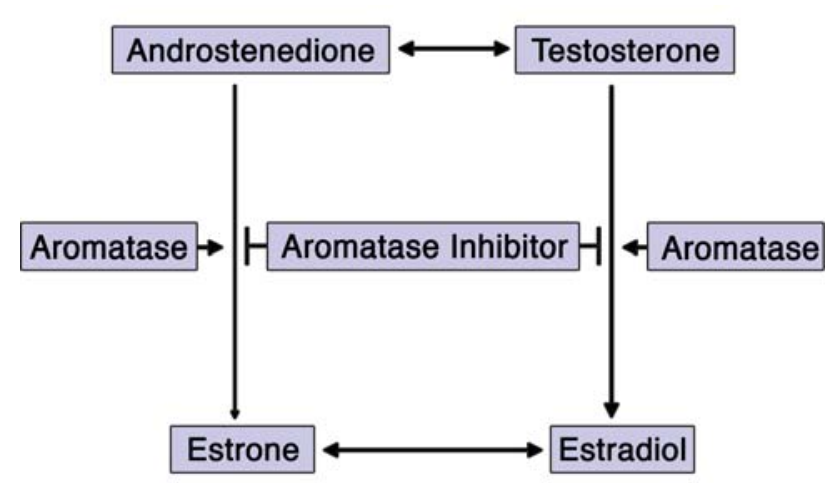

Figure 1. Mechanism of action of aromatase inhibitors. inhibitory properties allow their use without the need for supplemental corticosteroidal or mineralocorticoid supplementation, as is the case with the nonspecific $\mathrm{AI}$ aminoglutethimide.

Several clinical trials have evaluated the efficacy and safety of these agents. Here, we review the published literature regarding these trials and summarize advances in the hormonal treatment of breast cancer.

\section{AIs in Metastatic Breast Cancer}

Several phase III trials have shown that third-generation AIs are superior to megestrol acetate as second-line therapy in patients with tamoxifen-resistant metastatic breast cancer (MBC) (Table 2) [14-18]. In addition, Rose et al. [19] compared two third-generation AIs, letrozole and anastrozole, in a randomized trial of 713 postmenopausal patients with tamoxifen-resistant MBC. Forty-eight percent of the patients in each study group had hormonereceptor-positive tumors; for all others, the hormone receptor status was unknown. The overall response rate (ORR) for patients receiving letrozole was $19.1 \%$, compared with $12.3 \%$ for patients receiving anastrozole $(p=$ .014 ; odds ratio, 1.70). However, when the patients were stratified on the basis of confirmed hormone receptor positivity, the ORR did not significantly differ between the anastrozole (16.8\%) and letrozole (17.3\%) groups. Time to progression (TTP), overall survival (OS), duration of response, and duration of clinical benefit for the two groups did not significantly differ. Both drugs were associated with similar rates of adverse events.

\section{Anastrozole Versus Tamoxifen}

Several phase III studies have compared the efficacy of the third-generation AIs with that of tamoxifen as first-line therapy for MBC (Table 3) [20-24]. The Tamoxifen and Arimide ${ }^{\circledR}$ Randomized Group Efficacy and Tolerability (TARGET) trial is a multicenter randomized trial that was done simultaneously in Europe [23] and in North America [22]. The same study design was used to allow combined analysis of the data. It compared anastrozole with tamoxifen as first-line therapy for MBC, with the main end points being TTP, ORR, and OS.

Table 1. Classification of aromatase inhibitors

\begin{tabular}{lll}
\hline Generation & $\begin{array}{l}\text { Type 1 } \\
\text { (steroidal) }\end{array}$ & $\begin{array}{l}\text { Type 2 } \\
\text { (nonsteroidal) }\end{array}$ \\
\hline First & None & Aminoglutethimide \\
Second & Formestane & Fadrozole \\
Third & Exemestane & $\begin{array}{l}\text { Anastrozole } \\
\text { Letrozole } \\
\text { Vorozole }\end{array}$ \\
\hline
\end{tabular}


In the European TARGET, 154 (45.3\%) of 340 patients receiving anastrozole and 144 (43.9\%) of 328 patients receiving tamoxifen had ER-positive and/or PgR-positive tumors. The ORR was $33 \%$ in both groups, and the TTP was 8.2 months in the anastrozole group and 8.3 months in the tamoxifen group (no significant difference) [23].

In the North American TARGET, 151 (88.3\%) of the 171 patients treated with anastrozole $(1 \mathrm{mg} /$ day $)$ and 162 $(89.0 \%)$ of the 182 patients treated with tamoxifen (20 $\mathrm{mg}$ /day) had hormone-receptor-positive tumors. The ORR did not significantly differ: $21 \%$ in the anastrozole group and $17 \%$ in the tamoxifen group. The clinical benefit rate, however was significantly higher with anastrozole (59.1\%) than with tamoxifen (45.6\%; $p=.0098)$, but not the OS [24]. The TTP was 11.1 months in the anastrozole group and 5.6 months in the tamoxifen group $(p=.005)$.

On the basis of these two trials, anastrozole was approved as first-line therapy for MBC [23, 24]. Analysis of the combined patient population in both trials $(n=1,021$; median follow-up, 18.2 months) showed that anastro- zole was equivalent to tamoxifen in terms of median TTP (anastrozole, 8.5 months; tamoxifen, 7.0 months) and ORR (anastrozole, 29\%; tamoxifen, 27.1\%) (Table 3) [20]. Nevertheless, in the subset of patients whose tumors were positive for ER and/or PgR (thus excluding those with unknown receptor status) anastrozole was superior to tamoxifen with respect to TTP (median, 10.7 months for anastrozole and 6.4 months for tamoxifen; $p=.022$ ).

\section{Letrozole Versus Tamoxifen}

In a randomized trial by the International Letrozole Breast Cancer Group [21], letrozole and tamoxifen were compared as first-line therapy for MBC. Of 907 patients, 453 were randomized to receive letrozole $(2.5 \mathrm{mg} /$ day) and 454 to receive tamoxifen $(20 \mathrm{mg} /$ day $)$. The study design allowed for optional crossover of treatments when a patient's disease progressed. The patient and tumor characteristics were similar in the two arms of the study. Tumors were positive for ER and/or PgR in 599 (66\%) of the patients; all others' receptor status was unknown. The

Table 2. Phase III trials showing superiority of third-generation aromatase inhibitors to megestrol acetate as second-line therapy for patients with metastatic breast cancer resistant to tamoxifen

\begin{tabular}{|c|c|c|c|c|c|c|c|}
\hline Study & AI & $n$ & $\operatorname{ORR}(\%)^{\mathrm{a}}$ & $\begin{array}{l}\text { Clinical } \\
\text { benefit }(\%)^{\mathrm{a}}\end{array}$ & $\begin{array}{l}\text { Median } \\
\text { TTP }(\mathrm{mo})^{\mathrm{a}}\end{array}$ & $\begin{array}{l}\text { Median } \\
\text { OS }(\text { mo })^{\mathrm{a}}\end{array}$ & MDR $^{\mathbf{a}}$ \\
\hline Jonat et al. [16] & Anastrozole & 764 & 13 vs. 12 & 42 vs. 40 & 4.8 vs. 4.6 & $\begin{array}{l}27 \text { vs. } 23 \\
(p=.02)\end{array}$ & - \\
\hline Buzdar et al. [14] & Anastrozole & 378 & - & 34 vs. 33 & - & N/A & - \\
\hline Dombernowsky et al. [15] & Letrozole & 551 & $\begin{array}{l}24 \text { vs. } 16 \\
(p=.04)\end{array}$ & $\begin{array}{l}24 \text { vs. } 15 \\
(p=.001)\end{array}$ & 5.6 vs. 5.5 & N/A & $\begin{array}{l}\text { NR vs. } 18 \\
(p=.02)\end{array}$ \\
\hline Kaufmann et al. [18] & Exemestane & 769 & 15 vs. 12 & $\begin{array}{l}37 \text { vs. } 35 \\
(p=.025)\end{array}$ & $\begin{array}{l}4.7 \text { vs. } 3.8 \\
(p=.037)\end{array}$ & $\begin{array}{l}\text { NR vs. } 29 \\
(p=.039)\end{array}$ & 18 vs. 17 \\
\hline Buzdar et al. [17] & Letrozole & 602 & 16 vs. 15 & 27 vs. 23 & 3 vs. 3 & N/A & 25 vs. 30 \\
\hline
\end{tabular}

${ }^{a}$ Second value is for megestrol acetate.

Abbreviations: AI, aromatase inhibitor; MDR, median duration of response; N/A, not applicable; NR, not reached; ORR, overall response rate; OS, overall survival; TTP, time to progression.

Table 3. Phase III trials of aromatase inhibitors versus tamoxifen as first-line therapy for metastatic breast cancer

\begin{tabular}{|c|c|c|c|c|c|c|c|c|c|}
\hline Study & AI & $n$ & $\begin{array}{l}\text { ORR } \\
(\%)^{\mathrm{a}}\end{array}$ & $\begin{array}{l}\text { Clinical } \\
\text { Benefit } \\
(\%)^{a}\end{array}$ & $\begin{array}{l}\text { Median } \\
\text { TTP } \\
\text { (months) }^{\mathrm{a}}\end{array}$ & $\begin{array}{l}\text { Median } \\
\text { TTF } \\
\text { (months) }^{\mathrm{a}}\end{array}$ & $\begin{array}{l}\text { Median } \\
\text { OS } \\
\text { (months) }^{\mathrm{a}}\end{array}$ & $\begin{array}{l}\text { 1-Year } \\
\text { survival } \\
(\%)^{a}\end{array}$ & $\begin{array}{l}\text { 2-Year } \\
\text { survival } \\
(\%)^{a}\end{array}$ \\
\hline $\begin{array}{l}\text { Bonnettere } \\
\text { et al. [23] }\end{array}$ & Anastrozole & 668 & $\begin{array}{l}32.9 \text { vs. } \\
32.6\end{array}$ & 56.2 vs. 55.5 & $\begin{array}{l}8.2 \text { vs. } 8.3 \\
(p=.941)\end{array}$ & - & - & - & - \\
\hline $\begin{array}{l}\text { Nabholtz et } \\
\text { al. [24] }\end{array}$ & Anastrozole & 353 & 21 vs. 17 & 59 vs. 46 & $\begin{array}{l}11.1 \text { vs. } 5.6 \\
(p=.005)\end{array}$ & - & - & - & - \\
\hline $\begin{array}{l}\text { Bonneterre } \\
\text { et al. [20] }\end{array}$ & Anastrozole & 1021 & 29 vs. 27.1 & 57.1 vs. 52 & $\begin{array}{l}8.5 \text { vs. } 7.0 \\
(p=.103)\end{array}$ & - & - & - & - \\
\hline $\begin{array}{l}\text { Mouridsen } \\
\text { et al. [21] }\end{array}$ & Letrozole & 907 & $\begin{array}{l}32 \text { vs. } 21 \\
(p<.001)\end{array}$ & $\begin{array}{l}50 \text { vs. } 38 \\
(p<.001)\end{array}$ & 9.4 vs. 6.0 & $\begin{array}{l}9 \text { vs. } 5.7 \\
(p<.001)\end{array}$ & 34 vs. 30 & $\begin{array}{l}83 \text { vs. } 75 \\
(p=.004)\end{array}$ & $\begin{array}{l}62 \text { vs. } 57 \\
(p=.025)\end{array}$ \\
\hline $\begin{array}{l}\text { Paridaens et } \\
\text { al. [22] }\end{array}$ & Exemestane & 382 & 43 vs. 29 & 71 vs. 66 & - & $\begin{array}{l}10.9 \text { vs. } 6.7 \\
(p=.04)\end{array}$ & - & - & - \\
\hline
\end{tabular}

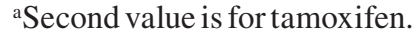

Abbreviations: AI, aromatase inhibitor; ORR, overall response rate; OS, overall survival; TTF, time to treatment failure; TTP, time to progression. 
median follow-up was 32 months. Letrozole was superior to tamoxifen with respect to TTP (median, 9.4 months vs. 6.0 months; $p<.001$ ); time to treatment failure (median, 9.0 vs. 5.7 months; $p<.001)$, ORR ( $32 \%$ vs. $21 \% ; p<.001)$, and clinical benefit (50\% vs. $38 \% ; p=.001$ ), and the OS rates at 1 and 2 years significantly favored letrozole [21]. Moreover, the total duration of endocrine therapy (time to chemotherapy) was significantly longer ( $p=.005$ ) for patients who initially took letrozole (median, 16 months) than for patients who initially took tamoxifen (median, 9 months). These data led to the approval of letrozole as first-line therapy for metastatic breast cancer [25].

\section{Exemestane Versus Tamoxifen}

A European Organization for Research and Treatment of Cancer phase III randomized trial [22] compared exemestane with tamoxifen in 382 postmenopausal patients who had received no prior hormone therapy for metastatic disease and had hormone receptor-positive or receptor-unknown breast cancer with a long disease-free interval after adjuvant therapy (Table 3 ). The ORR was $43 \%$ for exemestane and $29 \%$ for tamoxifen. The median progression-free survival time was significantly longer with exemestane (10.9 months) than with tamoxifen (6.7 months; $p=.04)$, with a hazard ratio (HR) of $0.79(95 \%$ confidence interval [CI], 0.62-0.99) in favor of exemestane [22].

The results of these studies show that AIs compare favorably with tamoxifen. Although tamoxifen had been the agent of choice for the first-line treatment of MBC for many years, AIs have now largely replaced it in this setting barring the presence of contraindications to its use, such as uncontrolled osteoporosis.

\section{AIs as AdJuVant Therapy}

Historically, tamoxifen has been the standard treatment for hormone receptor-positive breast cancer, resulting in a significant improvement in disease-free survival (DFS) regardless of nodal status [3]. Resistance to tamoxifen therapy in early breast cancer may occur as early as $12-18$ months after the initiation of therapy, and in some patients with resistant disease, tamoxifen can stimulate breast cancer cell growth [26]. Therefore, the role of more effective, less toxic agents, such as the third-generation AIs, has been evaluated in adjuvant therapy for early breast cancer.

Several adjuvant randomized studies of tamoxifen versus an AI as single agents or given in combination or sequentially have been conducted with the main objectives of comparing DFS and OS in postmenopausal patients with breast cancer (Table 4). A synopsis of these studies is discussed below.

\section{Arimidex ${ }^{\circledR}$, Tamoxifen, Alone or in Combination Study}

The Arimidex ${ }^{\circledast}$, Tamoxifen, Alone or in Combination (ATAC) trial is the largest hormonal adjuvant trial conducted to date for postmenopausal patients with early-stage breast cancer. It was designed as an international, randomized, double-blind, multicenter study for postmenopausal patients with histologically confirmed operable invasive breast cancers who had completed primary therapy and were candidates to receive adjuvant hormonal therapy. Patients were randomized in a 1:1:1 ratio among the three arms of the trial: (a) anastrozole plus placebo, (b) tamoxifen plus placebo, or (c) anastrozole plus tamoxifen. The first interim analysis, done after a median of 33 months, showed that anastrozole resulted in a significantly better DFS rate at 3 years than tamoxifen $(89.4 \%$ on anastrozole and $87.4 \%$ on tamoxifen; $p=.013$ ) and that the combination of tamoxifen and anastrozole was equivalent to tamoxifen alone, offering no efficacy or safety advantage. Thus the combination arm was closed. A second interim analysis, done after a median of 47 months, showed that anastrozole continued to be more effective than tamoxifen with respect to DFS (HR, $0.86 ; p=$ $.003)$ and the time to recurrence, new contralateral tumors, or death from any cause [27,28].

Table 5 summarizes the results of the third interim analysis that was presented at the 27th San Antonio Breast Cancer Symposium in 2004. After a median of 68 months, anastrozole was associated with better DFS (HR, $0.83 ; p=.005$ ), longer time to disease recurrence (HR, $0.74 ; p<.001$ ), and lower incidence of contralateral breast cancer (HR, 0.47; $p=.001)$ in women with hormone-receptor-positive disease. OS was similar between the two treatment groups [29].

Compared with tamoxifen, anastrozole was associated with fewer venous thromboembolic complications and ischemic cerebrovascular complications but more musculoskeletal symptoms. However, there was significantly higher fracture rates among patients receiving anastrazole. A complete risk-benefit analysis must await longer followup [30].

\section{Italian Tamoxifen and Anastrozole Trial}

Boccardo et al. [31] evaluated the strategy of hormonal therapy crossover from tamoxifen to anastrozole. Four hundred forty-eight patients who had been receiving tamoxifen $(20 \mathrm{mg} /$ day) for 2 or more years were randomly assigned to continue with tamoxifen for as long as a total of 5 years or to switch to anastrozole ( $1 \mathrm{mg} / \mathrm{day}$ ) for a comparable period. After a median of 3 years, 45 adverse events (locoregional recurrence, distant metastases, second primary tumors [including contralateral breast cancer], or death not related to breast cancer) were reported in the tamoxifen group 
Table 4. Main characteristics of randomized aromatase inhibitors versus tamoxifen trials in adjuvant therapy of postmenopausal, hormone-receptor-positive breast cancer

\begin{tabular}{|c|c|c|c|c|}
\hline & Letrozole & Anastrozole & Exemestane & Letrozole \\
\hline Trial name & BIG 1-98 [33] & ATAC [27-29] & IES $[34,35]$ & MA-17 [36] \\
\hline $\begin{array}{l}\text { Interval between initial } \\
\text { treatment and aroma- } \\
\text { tase inhibitor adminis- } \\
\text { tration }\end{array}$ & $\begin{array}{l}\text { Adjuvant or after } 2 \text { years } \\
\text { of disease-free survival } \\
\text { under tamoxifen or } \\
\text { letrozole }\end{array}$ & Adjuvant & $\begin{array}{l}\text { After 2-3 years of } \\
\text { disease-free survival } \\
\text { under tamoxifen }\end{array}$ & $\begin{array}{l}\text { After } 5 \text { years of dis- } \\
\text { ease-free survival } \\
\text { under tamoxifen }\end{array}$ \\
\hline No. of patients & 8,010 & 9,366 & 4,742 & 5,187 \\
\hline \multirow[t]{3}{*}{ Treatment arms } & Letrozole, $2.5 \mathrm{mg}$ & Anastrozole, $1 \mathrm{mg}$ & Exemestane, $25 \mathrm{mg}$ & Letrozole, $2.5 \mathrm{mg}$ \\
\hline & Tamoxifen, $20 \mathrm{mg}$ & Tamoxifen, $20 \mathrm{mg}$ & $\begin{array}{l}\text { Tamoxifen, } \\
20 \text { or } 30 \mathrm{mg}\end{array}$ & Placebo \\
\hline & & Combination & & \\
\hline Blinding & $\begin{array}{l}\text { Double-blind double- } \\
\text { dummy }\end{array}$ & Double-blind & Double-blind & Double-blind \\
\hline $\begin{array}{l}\text { Planned treatment } \\
\text { duration }\end{array}$ & 5 years & 5 years & 5 years & 5 or 10 years \\
\hline $\begin{array}{l}\text { Estrogen receptor } \\
\text { status lacking }\end{array}$ & $0.2 \%$ & $8 \%$ & $17 \%$ & $<1 \%$ \\
\hline Primary end point & Disease-free survival & Disease-free survival & Disease-free survival & Disease-free survival \\
\hline Secondary end point & $\begin{array}{l}\text { Time to recurrence, inci- } \\
\text { dence of contralateral } \\
\text { breast tumors, second } \\
\text { malignancy (nonbreast) } \\
\text { distant recurrence, and } \\
\text { overall survival }\end{array}$ & $\begin{array}{l}\text { Time to recurrence, } \\
\text { incidence of contra- } \\
\text { lateral breast tumors, } \\
\text { distant recurrence, } \\
\text { and overall survival }\end{array}$ & $\begin{array}{l}\text { Long-termtoler- } \\
\text { ability, incidence of } \\
\text { contralateral breast } \\
\text { cancer, and overall } \\
\text { survival }\end{array}$ & $\begin{array}{l}\text { Quality of life, long- } \\
\text { term safety, and over- } \\
\text { all survival }\end{array}$ \\
\hline Median follow-up & $35.5 \mathrm{mos}$ & $47 \mathrm{mos}$ & $37.4 \mathrm{mos}$ & $28 \mathrm{mos}$ \\
\hline
\end{tabular}

Abbreviations: ATAC, Arimidex ${ }^{\circledR}$, Tamoxifen, Alone or in Combination; BIG, Breast International Group; IES, Intergroup Exemestane Study.

Table 5. Summary of Arimidex ${ }^{\circledR}$, Tamoxifen, Alone or in Combination (ATAC) trial

\begin{tabular}{lll}
\hline & Hazard ratio $(95 \%$ CI $)$ & $p$-value \\
\hline $\begin{array}{l}\text { Disease-free } \\
\text { survival }\end{array}$ & & \\
$\quad$ ITT population & $0.87(0.78-0.97)$ & .01 \\
HR $^{+}$population & $0.83(0.73-0.94)$ & .005 \\
$\begin{array}{l}\text { Incidence of new } \\
\text { contralateral pri- } \\
\text { mary breast tumors }\end{array}$ & & \\
$\quad$ ITT population & $0.58(0.38-0.88)$ & .01 \\
$\quad$ HR ${ }^{+}$population & $0.47(0.29-0.75)$ & .001 \\
Time to recurrence & & \\
ITT population & $0.79(0.70-0.90)$ & $<.001$ \\
HR $^{+}$population & $0.74(0.64-0.87)$ & $<.001$ \\
\hline
\end{tabular}

${ }^{\mathrm{a}} p$-value is for comparison between anastrozole and tamoxifen. Abbreviations: CI, confidence interval; HR, hormone receptor; ITT, intention to treat.

Data from Howell A, on behalf of the ATAC Trialists' group. ATAC ('Arimidex', Tamoxifen, Alone or in Combination) completed treatment analysis: anastrozole demonstrates superior efficacy and tolerability compared with tamoxifen. Breast Cancer Res Treat 2004;88(suppl 1):7, with permission. compared with 17 adverse events in the anastrozole group $(p<.001)$. DFS and local recurrence-free survival were also significantly longer in the anastrozole group (HR, 0.35;95\% CI, 0.18-0.68; $p=.001$ and HR, 0.15; 95\% CI, 0.03-0.65; $p=.003$, respectively).

\section{Austrian Breast Cancer Study Group and Arimidex ${ }^{\circledR}$-Nolvadex ${ }^{\circledR}$ Trials-Pooled Analysis}

The Austrian Breast Cancer Study Group (ABCSG) and Arimidex ${ }^{\circledR}$-Nolvadex ${ }^{\circledR}$ (ARNO) trials were similar in design, and both were conducted to determine whether switching to anastrozole after 2 years of tamoxifen treatment was more effective than continuing tamoxifen for the remaining 3 years of adjuvant therapy in postmenopausal patients with hormone-receptor-positive, operable breast cancer [32]. No patients received chemotherapy before the hormonal treatment. The two trials enrolled 3,224 women (mean age, 63 years). After completion of 2 years of tamoxifen, patients were randomized to continue tamoxifen $(n=1,606)$ or to receive anastrozole $(n=1,618)$ for the next 3 years. A total of $27 \%$ of patients had posi- 
tive nodes, and $100 \%$ had hormone-receptor-positive disease (i.e., ER- and/or PgR-positive). After a median of 28 months, 67 events (locoregional recurrence, contralateral breast cancer, or distant recurrence) had occurred among patients switched to anastrozole compared with 110 events in the tamoxifen-only group. The HR for event-free survival with anastrozole versus tamoxifen was $0.60(p<$ $.001)$. There were significantly more fractures $(p=.015)$ and significantly fewer thromboses $(p=.034)$ in patients treated with anastrozole than in those on tamoxifen. Thus, the data suggest that switching to anastrozole after 2 years of tamoxifen is more effective than treatment with tamoxifen alone.

\section{Breast International Group 1-98 Trial}

The Breast International Group (BIG) 1-98, a multinational phase III double-blind, randomized multicenter trial, was initially designed to compare 5 years of tamoxifen with 5 years of letrozole adjuvant therapy [33]. After an accrual of 1,835 patients, the study was amended to add 2 additional arms: 2 years of tamoxifen, followed by 3 years of letrozole, and 2 years of letrozole followed by 3 years of tamoxifen. A total of 8,010 postmenopausal women with hormone-receptor-positive early breast cancer were randomized (4,003 patients started with letrozole and 4,007 with tamoxifen). The primary objective of the study was to evaluate the DFS events defined as breast cancer relapse, occurrence of contralateral invasive breast carcinoma or a second nonbreast malignancy, or death without recurrence. The median follow-up was 25.8 months. The median age of the patients in both groups was 61 years, and approximately half of the patients had node-negative disease. About $40 \%$ of the women had breast cancers that were smaller than 2 $\mathrm{cm}$ ), and $25 \%$ of the women had received chemotherapy. The first interim analysis compared all patients who were started on tamoxifen or letrozole. Approximately 63\% of breast cancers were positive for both ER and PgR, and approximately $20 \%$ were positive for ER and negative for PgR. DFS favored patients treated with letrozole (HR, 0.81; $p=.003$ ), as did systemic DFS (HR, $0.83 ; p=.016$ ). There was an absolute difference in breast cancer recurrence of $3.4 \%$ at 5 years $(13.6 \%$ with tamoxifen vs. $10.2 \%$ with letrozole; $p<.001)$. In addition, both time to relapse (HR, $0.72 ; p<.001)$ and time to distant metastases (HR, 0.73; $p=.0012$ ) favored the letrozole group. No significant difference in OS had been detected at the time of this early analysis (HR, $0.86 ; p=.16)$. There was a trend toward a higher 5-year incidence of death without recurrence in the letrozole group, but it did not reach statistical significance $(3.1 \%$ vs. $1.8 \% ; p=.08)$. In particular, the number of cerebrovascular accident deaths (7 vs. 1) and cardiac deaths (13 vs. 6) were higher with letrozole. However, the incidence of grade 3-5 cerebrovascular accidents or transient ischemic attacks was approximately $1 \%$ in both groups, and the incidence of other grade 3-5 cardiovascular events was $3.2 \%$ with letrozole and $23 \%$ with tamoxifen. Grade 3-5 thromboembolic events occurred in $2.0 \%$ of the patients treated with tamoxifen versus $0.7 \%$ of those treated with letrozole. In general, most adverse events (any grade) were similar between the groups, with the exception of hypercholesterolemia, which was higher with letrozole (5.4\% vs. $1.2 \%)$. Bone fractures also occurred more frequently with letrozole $(5.8 \%$ vs. $4.1 \%$; odds ratio, $1.44 ; p<.001)$. There was trend toward fewer invasive endometrial cancers with letrozole $(0.2 \%$ vs. $0.4 \%$; odds ratio, $0.40 ; p=.078)$. These results provide further support for the use of an AI as initial therapy for postmenopausal patients with early-stage hormone receptor-positive breast cancer. The question of whether sequencing tamoxifen and an $\mathrm{AI}$ is superior to $\mathrm{AI}$ monotherapy is unknown, and results of the full BIG 1-98 trial will provide valuable insight into this important clinical question. Although the difference in cardiovascular complications could be due in part to the protective effect of tamoxifen, this needs close observation and further follow-up to fully evaluate the risks and benefits of the hormonal therapy options.

\section{Intergroup Exemestane Study}

The Intergroup Exemestane Study is a double-blind, randomized trial designed to compare 5 years of tamoxifen with 2-3 years of tamoxifen followed by 3-2 years of exemestane [34]. A total of 4,742 patients was enrolled; 2,362 patients were randomly assigned to switch to exemestane and 2,380 to continue receiving tamoxifen. The primary end point was DFS, and the secondary end points included OS, the incidence of contralateral breast cancer, and long-term tolerability. At the first interim analysis, done after a median of 30.6 months, exemestane reduced the risk for recurrence by $32 \%$ ( $\mathrm{HR}, 0.68 ; 95 \% \mathrm{CI}$, $0.56-0.82 ; p<.001)$ and was associated with an absolute DFS benefit of $4.7 \%$ at 3 years from randomization $(95 \%$ CI, 2.6-6.8). OS was not significantly different between the two groups [34]. A second interim analysis was done after a median of 37.4 months and showed that switching to exemestane improved DFS by almost $30 \%$ (HR, 0.73; 95\% CI, 0.56-0.82; $p<.001)$. Furthermore, switching to exemestane significantly reduced the risk for contralateral breast cancer $(p=.04)$ and the incidence of ipsilateral breast cancer recurrence $(p<.001)$. The use of exemestane was associated with a higher incidence of musculoskeletal side effects but a lower risk for adverse gynecologic and thromboembolic sequelae [35]. 


\section{Extended Adjuvant Hormonal MA-17 Study}

The MA-17 study randomized a total of 5,147 patients who had completed 5 years of adjuvant tamoxifen to receive either letrozole $(2,575)$ or placebo $(2,572)$ for an additional 5 years [36]. The goal of the study was to evaluate the value of extended adjuvant hormonal therapy, and the study was powered to show a $2.5 \%$ difference in DFS at 4 years.

The first planned interim analysis was done after 207 events and a median follow-up of 2.4 years; when projected over 4 years, there was a significantly lower recurrence rate in the letrozole group compared with the placebo group (HR, 0.57; 95\% CI, 0.43-0.75; $p<.001$ ). This difference was significant for both the node-positive and the nodenegative groups. The node-positive patients receiving letrozole had significantly longer OS than those receiving placebo [37]. Grade 1 and 2 hot flashes, arthritis, arthralgia, and myalgia were more frequent in the letrozole group, but vaginal bleeding was less frequent. In the letrozole group, $5.8 \%$ of the women had new diagnoses of osteoporosis compared with $4.5 \%$ in the placebo group $(p=.07)$. The quality of life did not differ between the two groups.

The American Society of Clinical Oncology Technology Assessment Working Group states that, based on results from multiple large randomized trials, adjuvant therapy for postmenopausal women with hormone receptor-positive breast cancer should include an AI in order to lower the risk for tumor recurrence. Neither the optimal timing nor duration of AI therapy is established. AIs are appropriate as initial treatment for women with contraindications to tamoxifen. For all other postmenopausal women, treatment options include 5 years of AI treatment or sequential therapy consisting of tamoxifen (for either 2-3 years or 5 years) followed by AIs for 2-3 or 5 years. Patients intolerant of AIs should receive tamoxifen. There are no data on the use of tamoxifen after an aromatase inhibitor in the adjuvant setting. AIs are contraindicated in premenopausal women; there are limited data concerning their role in women with treatment-related amenorrhea. The side effect profiles of tamoxifen and AIs differ. The late consequences of AI therapy, including osteoporosis, are not well characterized [38].

\section{AIs as NeOADJUVAnt Therapy}

Several studies have investigated the efficacy of AIs as neoadjuvant therapy for hormone receptor-positive breast cancers. In a phase II trial, 112 postmenopausal women with locally advanced ER-positive breast cancer were treated with neoadjuvant anastrozole [39]. Fifty-five percent of the patients had complete clinical responses, and $29 \%$ had partial clinical responses. However, an impressive $23 \%$ of the patients had complete pathologic responses.
In a phase III randomized trial, 324 postmenopausal patients with stage II or III hormone receptor-positive breast cancer were treated with letrozole or tamoxifen as neoadjuvant therapy [40]. The clinical response rate to letrozole was significantly higher than to tamoxifen $(55 \%$ vs. $36 \% ; p<.001)$. Patients receiving letrozole also had a higher incidence of breast-conserving surgery (Table 6). A reanalysis of the data according to HER-1 and HER-2 (ErbB-2) status revealed a marked difference in the clinical response rate to letrozole $(88 \%)$ and tamoxifen $(21 \%)$ in tumors that expressed ER and either HER-1 or HER-2 $(p<$ .001) (Table 7) [41].

The phase III Preoperative Arimidex ${ }^{\circledR}$ Compared with Tamoxifen (PROACT) trial is a randomized, double-blind study designed to evaluate the efficacy of 12 weeks of treatment with anastrozole versus tamoxifen as neoadjuvant therapy in 451 postmenopausal women with hormone receptor-positive breast tumors [42]. Additional preoperative chemotherapy was optional and was determined before randomization. The primary end point was the ORR as assessed by sonography after 12 weeks of therapy. Secondary end points included changes between originally planned surgeries and surgeries actually performed (from inoperable at baseline to mastectomy or breast-conserving surgery or from mastectomy at baseline to breast-conserving surgery). In the subset of patients who received only hormonal therapy $(n=314)$, $43 \%$ of those treated with anastrozole had improved surgical status in favor of breast-conserving surgery compared with $31 \%$ of those treated with tamoxifen $(p=.04)$ [42].

In the Immediate Preoperative Anastrozole, Tamoxifen, or Combined With Tamoxifen (IMPACT) trial, 330 postmenopausal women with ER-positive, invasive, operable breast cancer were randomized in a double-blinded fashion to 3 months of preoperative treatment with anastrozole, tamoxifen, or both. The ORR was $37.2 \%$ in the anastrozole group, $36.1 \%$ in the tamoxifen group, and $39.4 \%$ in the combination group. In patients who were assessed as requiring mastectomy at baseline $(n=124), 44 \%$ received breast-conserving surgery after anastrozole compared with $31 \%$ of those given tamoxifen ( $p=.23$ ); this difference became significant for patients who were deemed candidates for breast-conserving surgery by their surgeons $(46 \%$ vs. $22 \%$, respectively; $p=.03$ ). The ORR for patients with HER-2-positive cancer $(n=34)$ was $58 \%$ for anastrozole compared with $22 \%$ for tamoxifen $(p=.18)$. All treatments were well tolerated [43].

\section{AIs as Breast Cancer Preventive Agents}

Preclinical and clinical evidence suggests a major role for estrogen in the initiation and promotion of breast cancer. The Breast Cancer Prevention P-1 trial showed that 
Table 6. Results of a double-blind randomized trial of neoadjuvant letrozole versus tamoxifen for postmenopausal patients with hormone receptor-positive breast cancer

\begin{tabular}{llll}
\hline Characteristic & Letrozole $(\boldsymbol{n}=\mathbf{1 5 4})$ & Tamoxifen $(\boldsymbol{n}=\mathbf{1 7 0})$ & $\boldsymbol{p}$-value \\
\hline Overall tumor response $(\mathrm{CR}+\mathrm{PR})$ & & & $<.001$ \\
Clinical & $55 \%$ & $36 \%$ & .042 \\
$\quad$ Ultrasound & $35 \%$ & $25 \%$ & $<.001$ \\
$\quad$ Mammography & $34 \%$ & $16 \%$ & .022 \\
Breast-conserving surgery & $45 \%$ & $35 \%$ & \\
\hline
\end{tabular}

Abbreviations: CR, complete response; $\mathrm{PR}$, partial response.

Data from Eiermann W, Paepke S, Appfelstaedt J et al. Preoperative treatment of postmenopausal breast cancer patients with letrozole: a randomized double-blind multicenter study. Ann Oncol 2001;12:1527-1532, by permission of Oxford University Press.

Table 7. Clinical response of ER-positive breast cancers to letrozole versus tamoxifen according to HER-1 and HER-2 status

\begin{tabular}{lllll}
\hline Category & Letrozole & Tamoxifen & Odds ratio $(95 \%$ CI) & $p$-value \\
\hline HER-1/2, ER $^{+}$ & $15 / 17(88 \%)$ & $4 / 19(21 \%)$ & $28(4.5-177)$ & $<.001$ \\
HER-1 ${ }^{-} / 2^{-}, \mathrm{ER}^{+}$ & $55 / 101(54 \%)$ & $42 / 100(42 \%)$ & $1.7(0.9-2.9)$ & .0789 \\
\hline
\end{tabular}

Abbreviations: CI, confidence interval; ER, estrogen receptor.

Data from Ellis MJ, Coop A, Singh B et al. Letrozole is more effective neoadjuvant endocrine therapy than tamoxifen for ErbB1- and/or ErbB-2-positive, estrogen receptor-positive primary breast cancer: evidence from a phase III randomized trial. J Clin Oncol 2001;19(18):3808-3816. Reprinted with permission from the American Society of Clinical Oncology.

tamoxifen reduced the incidence of invasive breast tumors by $49 \%$ and of preinvasive lesions by $50 \%$ in women at increased risk for breast cancer [44]. Data from the ATAC [27], MA-17 [36], and Intergroup Exemestane [34] trials showed that AIs reduced the incidence of contralateral breast cancer ( $43 \%$ in the ATAC trial, $46 \%$ in the MA- 17 study, and $56 \%$ in the Intergroup Exemestane study).

Several phase III trials of AIs in breast cancer prevention are under way. The International Breast Cancer Intervention Study-2 trial, a follow-up to the ATAC trial, is randomizing women at high risk for breast cancer to receive either anastrozole or placebo. The Italian Aromasin ${ }^{\circledR}$ prevention study, comparing exemestane with placebo, is enrolling BRCA 1 or 2 gene carriers who are postmenopausal and do not yet have breast cancer [45].

Data from clinical trials of AIs in advanced breast cancer and data that are emerging from clinical trials of the third-generation type 2 AIs (i.e., anastrozole, letrozole, and exemestane) as adjuvant therapy support further evaluation of this class of agents for their ability to reduce breast cancer risk [43].

\section{SAFETY OF AIs}

AIs appear to have a different safety profile from tamoxifen. They are associated with a lower incidence of vaginal bleeding or discharge, cerebrovascular events, and venous thromboembolic events, and no reported endometrial carcinomas to date. Conversely, tamoxifen causes fewer musculoskeletal symptoms and is associated with fewer fractures [46]. An analysis of the updated safety data from the
ATAC trial [47] performed after 37 months showed better tolerance of anastrozole except in musculoskeletal events. Analysis of the effect of 2 years of treatment on bone mineral density in a subset of 308 women showed that anastrozole was associated with bone loss, whereas tamoxifen was associated with an increase in bone mineral density [30]. While tamoxifen has been shown to improve lipid profiles, the AIs have a very different mode of action and do not possess the estrogen-agonistic effects of tamoxifen. At present, there are few data on the effects of AIs on lipid profiles. Clinical trials with anastrozole demonstrated no clinically relevant impact on lipid profiles in postmenopausal patients with advanced breast cancer. However, as lipid profiles are surrogate end points, the most appropriate end point is the incidence of cardiovascular events in long-term studies. This is of particular relevance in the treatment of early breast cancer, where endocrine agents may be used in the adjuvant setting for periods of 5 years or longer. Long-term adjuvant anastrozole treatment resulted in significantly fewer thromboembolic and cerebrovascular events and a similar incidence of ischemic cardiovascular events compared with tamoxifen. The effects of the other AIs on lipid levels are variable, and correlation with cardiovascular events is currently under investigation [48].

AIs should be prescribed with caution in patients with osteoporosis. Until practice guidelines are established, all patients receiving AIs as adjuvant therapy should also receive vitamin $\mathrm{D}$ and calcium supplements, be encouraged to exercise, and, when there is evidence of bone loss at baseline, receive oral bisphosphonate. 


\section{CONCLUSions}

AIs have been found to be equivalent or superior to megestrol acetate as second-line therapy for metastatic breast cancer. In the first-line setting, large phase III trials have shown that AIs ( anastrazole, letrozole, and exemestane ) are equivalent or superior to tamoxifen in women with metastatic disease. Similarly, when used in the neoadjuvant setting, they resulted in better overall response rates and a more conservative surgery rate than tamoxifen. Until we have prevention phase III trials comparing tamoxifen with AIs, tamoxifen remains the gold standard for prevention of breast cancer in high-risk groups.

In the adjuvant therapy setting, on the other hand, 5 years of tamoxifen is no longer accepted as the standard of care; the new standard is to use AIs as single agents or sequentially with tamoxifen. The hormonal adjuvant options to discuss with patients are: (a) 5 years of adjuvant anastrozole or letrozole, (b) 5 years of tamoxifen followed by 5 years of letrozole, (c) and crossover to exemestane or to anastrazole after 2-3 years of tamoxifen for a total of 5 years of therapy. While data support this approach, however, wide application is pending U.S. Food and Drug Administration approval; on the other hand, the indication for the use of extended adjuvant therapy with 5 years of letrozole after 5 years of tamoxifen or the use of letrozole monotherapy for 5 years was recently approved. In addition, whether 5 years of an AI alone or 5 years of sequential therapy is the more beneficial treatment approach awaits longer follow-up of the DFS and OS durations of the patients in the respective studies.

Finally, the side effects of the drugs should be discussed with the patients because each drug has a different toxicity profile, most notably would be osteoporosis.

\section{Disclosure of Potential Conflicts OF INTEREST}

The authors indicate no potential conflicts of interest.

\section{REFERENCES}

1 Beatson GT. On the treatment of inoperable cases of carcinoma of the mamma: suggestions for a new method of treatment, with illustrative cases. Lancet 1896;2:104-107.

2 Love RR, Barden HS, Mazess RB et al. Effect of tamoxifen on lumbar spine bone mineral density in postmenopausal women after 5 years. Arch Intern Med 1994;154:2585-2588.

3 Early Breast Cancer Trialists' Collaborative Group (EBCTCG). Effects of chemotherapy and hormonal therapy for early breast cancer on recurrence and 15-year survival: an overview of the randomised trials. Lancet 2005;365:1687-1717.

4 Cuzick J, Powles T, Veronesi U et al. Overview of the main outcomes in breast-cancer prevention trials. Lancet 2003;361:296-300.

5 Fisher B, Dignam J, Bryant J et al. Five versus more than five years of tamoxifen for lymph node-negative breast cancer: updated findings from the National Surgical Adjuvant Breast and Bowel Project B-14 randomized trial. J Natl Cancer Inst 2001;93:684-690.

6 Nelson LR, Bulun SE. Estrogen production and action. J Am Acad Dermatol 2001;45 (suppl3):S116-S124.

7 Evans CT, Ledesma DB, Schulz TZ et al. Isolation and characterization of a complementary DNA specific for human aromatase-system cytochrome P-450 mRNA. Proc Natl Acad Sci U S A 1986;83:6387-6391.

8 Lonning PE. Pharmacology of new aromatase inhibitors. Breast 1996;5:202-208.

9 Geisler J, King N, Anker G et al. In vivo inhibition of aromatization by exemestane, a novel irreversible aromatase inhibitor, in postmenopausal breast cancer patients. Clin Cancer Res 1998;4:2089-2093.

10 Goss PE, Strasser K. Aromatase inhibitors in the treatment and prevention of breast cancer. J Clin Oncol 2001;19:881-894.

11 Lamb HM, Adkins JC. Letrozole: a review of its use in postmenopausal women with advanced breast cancer. Drugs 1998;56:1125-1140.

12 Wiseman LR, Adkins JC. Anastrozole: a review of its use in the management of postmenopausal women with advanced breast cancer. Drugs Aging 1998;13:321-332.
13 Lonning PE. Pharmacological profiles of exemestane and formestane, steroidal aromatase inhibitors used for treatment of postmenopausal breast cancer. Breast Cancer Res Treat 1998;49 (suppl 1):S45-S52.

14 Buzdar AU, Jonat W, Howell A et al. Anastrozole versus megestrol acetate in the treatment of postmenopausal women with advanced breast carcinoma: results of a survival update based on a combined analysis of data from two mature phase III trials. Arimidex Study Group. Cancer 1998;83:1142-1152.

15 Dombernowsky P, Smith I, Falkson G et al. Letrozole, a new oral aromatase inhibitor for advanced breast cancer: double-blind randomized trial showing a dose effect and improved efficacy and tolerability compared with megestrol acetate. J Clin Oncol 1998;16:453-461.

16 Jonat W, Howell A, Blomqvist C et al. A randomised trial comparing two doses of the new selective aromatase inhibitor anastrozole (Arimidex) with megestrol acetate in postmenopausal patients with advanced breast cancer. Eur J Cancer 1996;32A:404-412.

17 Buzdar A, Douma J, Davidson N et al. Phase III, multicenter, doubleblind, randomized study of letrozole, an aromatase inhibitor, for advanced breast cancer versus megestrol acetate. J Clin Oncol 2001;19:3357-3366.

18 Kaufmann M, Bajetta E, Dirix LY et al. Exemestane is superior to megestrol acetate after tamoxifen failure in postmenopausal women with advanced breast cancer: results of a phase III randomized double-blind trial. J Clin Oncol 2000;18:1399-1411.

19 Rose C, Vtoraya O, Pluzanska A et al. Letrozole (Femara) versus anastrozole (Arimidex): second-line treatment in postmenopausal women with advanced breast cancer. Proc Am Soc Clin Oncol 2002;21:34a.

20 Bonneterre J, Buzdar A, Nabholtz JMA et al. Anastrozole is superior to tamoxifen as first-line therapy in hormone receptor positive advanced breast carcinoma: results of two randomized trials designed for combined analysis. Cancer 2001;92:2247-2258.

21 Mouridsen H, Gershanovich M, Sun Y et al. Phase III study of letrozole versus tamoxifen as first-line therapy of advanced breast cancer in postmenopausal women: analysis of survival and update of efficacy from the International Letrozole Breast Cancer Group. J Clin Oncol 2003;21:2101-2109. 
22 Paridaens R, Therasse P, Dirix L et al. First line hormonal treatment (HT) for metastatic breast cancer (MBC) with exemestane (E) or tamoxifen (T) in postmenopausal patients (pts) - A randomized phase III trial of the EORTC Breast Group. Proc Am Soc Clin Oncol 2004;23:6.

23 Bonneterre J, Thurliman B, Robertson JF et al. Anastrozole versus tamoxifen as first-line therapy for advanced breast cancer in 668 postmenopausal women: results of Tamoxifen or Arimidex Randomized Group Efficacy and Tolerability study. J Clin Oncol 2000;18:3748-3757.

24 Nabholtz JM, Buzdar A, Pollak M et al. Anastrozole is superior to tamoxifen as first-line therapy for advanced breast cancer in postmenopausal women: results of a North American multicenter randomized trial. J Clin Oncol 2000;18:3758-3767.

25 Cohen MH, Johnson JR, Li N et al. Approval summary: letrozole in the treatment of postmenopausal women with advanced breast cancer. Clin Cancer Res 2002;8:665-669.

26 Osborne CK, Schiff R. Growth factor receptor cross-talk with estrogen receptor as a mechanism for tamoxifen resistance in breast cancer. Breast $2003 ; 12: 362-367$.

27 Baum M, Buzdar AU, Cuzick J et al. Anastrozole alone or in combination with tamoxifen versus tamoxifen alone for adjuvant treatment of postmenopausal women with early breast cancer: first results of the ATAC randomised trial. Lancet 2002;359:2131-2139.

28 Baum M, Buzdar A, Cuzick J et al. Anastrozole alone or in combination with tamoxifen versus tamoxifen alone for adjuvant treatment of postmenopausal women with early-stage breast cancer: results of the ATAC (Arimidex, Tamoxifen Alone or in Combination) trial efficacy and safety update analyses. Cancer 2003;98:1802-1810.

29 Howell A, on behalf of the ATAC Trialists' group. ATAC ('Arimidex', Tamoxifen, Alone or in Combination) completed treatment analysis: anastrozole demonstrates superior efficacy and tolerability compared with tamoxifen. Breast Cancer Res Treat 2004;88(suppl 1):7.

30 Howell A, on Behalf of the ATAC Trialists Group. Effect of anastrozole on bone mineral density: 2-year results of the Arimidex (anastrozole), tamoxifen, alone or in combination (ATAC) trial. Breast Cancer Res Treat 2003;82(suppl 1):27.

31 Boccardo F, Rubagotti A, Puntoni M et al. Switching to anastrozole versus continued tamoxifen of early breast cancer: preliminary results of the Italian Tamoxifen Anastrozole Trial. J Clin Oncol 2005;23:5138-5147.

32 Jakesz R, Jonat W, Gnant M et al. Switching of postmenopausal women with endocrine-responsive early breast cancer to anastrozole after 2 years' adjuvant tamoxifen: combined results of ABCSG trial 8 and ARNO 95 trial. Lancet 2005;366:455-462.

33 Thurlimann BJ, Keshaviah A, Mouridsen et al. BIG 1-98: randomized double-blind phase III study to evaluate letrozole (L) versus tamoxifen (T) as adjuvant endocrine therapy for postmenopausal women with receptorpositive breast cancer. J Clin Oncol 2005;23:6s.

34 Coombes RC, Hall E, Gibson LJ et al. A randomized trial of exemestane after two to three years of tamoxifen therapy in postmenopausal women with primary breast cancer. N Engl J Med 2004;350:1081-1092.

35 Coombes RC, Hall E, Snowdon CF et al. The Intergroup Exemestane Study: a randomized trial in postmenopausal patients with early breast cancer who remain disease-free after two to three years of tamoxifen-updated survival analysis. Breast Cancer Res Treat 2004;88(suppl 1):7.
36 Goss PE, Ingle JN, Martino S et al. A randomized trial of letrozole in postmenopausal women after five years of tamoxifen therapy for early-stage breast cancer. N Engl J Med 2003;349:1793-1802.

37 Goss PE, Ingle JN, Martino S et al. Updated analysis of the NCIC CTG MA.17 randomized placebo $(\mathrm{P})$ controlled trial of letrozole $(\mathrm{L})$ after five years of tamoxifen in postmenopausal women with early stage breast cancer. Proc Am Soc Clin Oncol 2004;23:87.

38 Winer EP, Hudis C, Burstein HJ et al. American Society of Clinical Oncology technology assessment on the use of aromatase inhibitors as adjuvant therapy for postmenopausal women with hormone receptor-positive breast cancer: status report 2004. J Clin Oncol 2005;23:619-629.

39 Milla-Santos A, Milla L, Calvo N et al. Anastrozole as neoadjuvant therapy for patients with hormone-dependent, locally-advanced breast cancer. Anticancer Res 2004;24:1315-1318.

40 Eiermann W, Paepke S, Appfelstaedt J et al. Preoperative treatment of postmenopausal breast cancer patients with letrozole: a randomized double-blind multicenter study. Ann Oncol 2001;12:1527-1532.

41 Ellis MJ, Coop A, Singh B et al. Letrozole is more effective neoadjuvant endocrine therapy than tamoxifen for ErbB-1- and/or ErbB-2-positive, estrogen receptor-positive primary breast cancer: evidence from a phase III randomized trial. J Clin Oncol 2001;19:3808-3816.

42 Cataliotti L, Buzdar A, Noguchi S et al. Efficacy of Pre-Operative Arimidex (anastrozole) Compared with Tamoxifen (PROACT) as neoadjuvant therapy in postmenopausal women with hormone receptor-positive breast cancer. Eur J Cancer 2004;2(suppl):A46.

43 Smith I, Dowsett M, Ebbs SR et al. Neoadjuvant treatment of postmenopausal breast cancer with anastrozole, tamoxifen, or both in combination: the Immediate Preoperative Anastrozole, Tamoxifen, or Combined with Tamoxifen (IMPACT) multicenter double-blind randomized trial. J Clin Oncol 2005;23:5108-5116.

44 Fisher B, Costantino JP, Wickerham DL et al. Tamoxifen for prevention of breast cancer: report of the National Surgical Adjuvant Breast and Bowel Project P-1 Study. J Natl Cancer Inst 1998;90:1371-1388.

45 Come SE, Buzdar AU, Arteaga CL et al. Proceedings of the third international conference on recent advances and future directions in endocrine manipulation of breast cancer: conference summary statement. Clin Cancer Res 2004;10:327S-330S.

46 Dowsett M. Origin and characteristics of adverse events in aromatase inhibition therapy for breast cancer. Semin Oncol 2003;30(suppl 14): 58-69.

47 Sainsbury R, on Behalf of the ATAC Trialists` Group. Beneficial sideeffect profile of anastrozole compared with tamoxifen confirmed by additional 7 months of exposure data: a safety update from the "Arimidex", Tamoxifen, Alone or in Combination (ATAC) trial. Breast Cancer Res Treat 2002;76(suppl 1):156.

48 Esteva FJ, Hortobagyi GN. Comparative assessment of lipid effects of endocrine therapy for breast cancer: implications for cardiovascular disease prevention in postmenopausal women. Breast doi:10.1016/ j.breast.2005.08.033. 